\title{
IMPACT OF INADVERTENT INTERCHANGE PRICING IN DEREGULATED POWER SECTOR
}

\author{
Ved Parkash', Yog Raj Sood ${ }^{2}$ \\ ${ }^{1}$ Research Scholar, ${ }^{2}$ Professor, Electrical Department, NIT Hamirpur \\ ved_park@yahoo.co.in,yrsood@gmail.com
}

\begin{abstract}
This paper proposes an approach for analysis and determination of inadvertent interchange based on Frequency Based Tariff for competitive electricity market. In this paper, combined model consisting of the pool, bilateral and multilateral transaction of deregulated power sector has been considered [11]. In competitive electricity market, power schedule is decided 24 hours ahead of real market but it has been observed that some of the market participants are diverted from their commitments regarding either supply of scheduled generation or withdrawal of scheduled load from the pool. Due to these reasons, the power system deviates from the optimized solutions. So there is an urgent need for determination of inadvertent interchange revenue paid by such defaulter market participants. In this paper, frequency based technique has been applied for determination of inadvertent interchange revenue paid by such defaulter market participants. The frequency based technique has been applied to double auction modified IEEE-30 bus test system. The whole transmission system has been divided into three sections; prevailing frequency in these regions can be assumed due to inadvertent interchange occurring in the system. In this paper, Frequency based tariff has been proposed for implementation to generalized deregulated model consisting of the pool, bilateral and multilateral transaction.
\end{abstract}

Keywords: Availability Based Tariff, Deregulated Power Sector, Independent System Operator, Competitive Electricity Market, Inadvertent Interchange, Central Electricity Regulatory Commission, Locational Marginal Price. $* * *$

\section{INTRODUCTION}

The main objective of the deregulated power sector market [1] is to decrease the cost of electricity through competition. The market environment typically consists of a pool and privately negotiated contracts. The performance of a market is measured by its social welfare, also called social benefit (SB). Social benefit is the difference of society's willingness to pay for energy and its cost. So in the deregulated environment, the objective functions consist of bid functions offered by generation companies and retailers to the independent system operator (ISO). The term Availability Based Tariff stands for a rational tariff structure for power supply from generating stations, on a contracted basis [2,3]. The unique feature of this tariff, to tackle the peculiar problems of grid operation in India, is the frequency-linked pricing of the Unscheduled Interchange (UI). In ABT mechanism, fixed and variable cost components of power plant are treated separately. Unscheduled Interchange [4] in a time block for a generating station/load means its total actual generation/demand minus its total scheduled generation/total scheduled drawal. All payments on account of Unscheduled Interchange charges levied under Grid regulations and these shall be utilized for serving of investment of transmission schemes or for providing ancillary services including but not only limited to load generation balancing during low grid frequency to ensure grid security and safety.
Indian energy exchange is India's first electricity exchange [5]. It is a transparent, neutral, nationwide, automated, online electricity trading platform. It enables efficient price discovery and price risk management for participants of the electricity market including industries eligible for open access through anonymous platform.

The Indian Electricity Grid Code (IEGC) is a regulation made by the Central Electricity Regulatory Commission [6]. It lays down the rules, guidelines and standards to be followed by various persons and participants in the system to plan, develop, maintain and operate the power system, in the most secure, reliable, economic and efficient manner, while facilitating healthy competition in the generation and supply of electricity. India has a huge power shortage (unmet electricity demand), which is retarding the nation's progress. The mechanism of Unscheduled Interchange (UI) [7, 8] if properly deployed, can help in bringing more power into the electricity grids, enabling the utilities to meet additional consumer load, both short-term and long-term, and significantly reduce the quantum of loadshedding. UI has generally been known as the third component Availability Based Tariff (ABT), which was introduced in India at the regional level in 2002-03. A real-time balancing market based on real-time price signals derived from frequency to maintain system frequency sufficiently close to nominal value has been proposed [9]. It is used for settlement of real-time imbalance between demand and supply during a trading period 
in deregulated markets. A frequency-linked bidding structure for the frequency regulation service market has been proposed [10]. A dynamic simulation model is developed for a two-area interconnected power system that incorporates the features of frequency regulation services to examine the performance of the optimum regulation contracts.

Conventional Generation Scheduling GS algorithm is modified to incorporate frequency dependant part of tariff [12]. Hourly frequency and load using Statistical Analysis and Artificial Neural Network (ANN) respectively are estimated. A technique for determining loop flows and designating contribution factors to utilities in a power system has been discussed [13]. Contribution factors are used to assess the participation of generating utilities in causing unscheduled flow and assigning equitable charge or compensation to utilities based on participation. In a competitive electricity market [14], the sellers and buyers submit bids for energy buy and sell. The bids are generally in the form of price and quantity quotations and specify how much seller or buyer is willing to buy or sell and at what price. After the bids are available to the market operator it settles the market based on optimization.

Frequency-based tariffs have been proposed in India to improve unscheduled interchange [15], [16]. Such tariffs apply steeply inclined prices to deviations from frequency. A very low price is assigned to high frequencies, and a very high price is assigned to low frequencies. The Wide Open Load Following (WOLF) Method is similar to the UI Pricing Method except that it includes time error, steeper prices, and a continuous pricing formula for reactive power [15]. Prices also vary with location due to line losses and transmission constraints [15], [17] and [18]. Thus, WOLF provides a technique for compensating specifically for unscheduled transmission usage unlike the UI Pricing Method.[13], [19] introduce a technique that shifts the focus from contributions of transmission companies to contributions of GENCOs specifically. The difference between actual flows and scheduled flows along different contract paths is used to estimate minor loop flows in an energy grid using various techniques to minimize the pth norm, such as ordinary least squares, robust regression. Contribution factors with different weighting mechanisms for each utility are then determined [20]. A suggested "take-orpay" charge could then be levied to participating GENCOs according to their unscheduled flow contribution as estimated using the minor loop flow assumptions and associated errors [21]. Availability Based Tariff comprises of three components: (a) Capacity Charge (b) Energy Charge (c) Unscheduled Interchange (UI) Charge. In case there are deviations from the schedule of generation or withdrawal of power, this third component of ABT comes into picture. Deviations from schedule are determined in 15-minute time blocks through special metering and priced according to the system condition prevailing at that time. If the frequency is above $50 \mathrm{~Hz}$, (nominal frequency in Indian System), UI rate will be low and if it is below $50 \mathrm{~Hz}$, it will be high. As long as the actual generation / drawal is according to the given schedule, the third component of ABT is zero. In case of deviation, market participants have to pay UI charge according to the specified frequency dependent rate. According to current guidelines of CERC, this rate varies in frequency range of $49.5 \mathrm{~Hz}$ and 50.2 $\mathrm{Hz}$.

This paper proposes an approach based on frequency based tariff for determination of inadvertent interchange revenue as penalty for defaulter demand market participants and profit for generator participants who provides extra power for stabilization to the system in competitive electricity market. This frequency based approach has been applied to a generalized model consisting of the pool and transactions such as firm bilateral and multilateral for competitive electricity market [11]. The proposed frequency based technique has been analyzed on modified IEEE-30 bus double auction test system. In the considered model, generation as well demand market participants are allowed to offer and bid their prices along with their maximum generation/demand limits to an independent system operator (ISO). The bilateral and multilateral transactions holders will request the ISO through a scheduling coordinator (SC) for transaction of power specifying the injections and extractions point as well as the amount of the transaction.

\section{MATHEMATICAL FORMULATION OF PROPOSED TECHNIQUE}

A methodology based on frequency linked tariff has been formulated which will be helpful for assessment of inadvertent interchange payment paid by the defaulter market participants in deregulated power sector. Previous work on handling inadvertent interchanges in a classical power system has been extended and developed a solution methodology clearly depicting how to handle these inadvertent interchanges in a deregulated power market. This new balancing mechanism is similar to a tariff scheme working successfully in India since 2002 and is based on real-time price signals derived from frequency. The generators and loads under this framework can self-schedule themselves based on real-time price signals maximizing their benefit. This scheme does not require any additional control and communication infrastructure as price is communicated by means of frequency that can be sensed anywhere in the grid. Penalty imposed on the defaulter market participants depend on severity of deviation. It will be paid if generator generates less than the schedule, or load overdraws power, thereby decreasing frequency.The Proposed Technique involves the following three steps:-

\subsection{Assumption of Frequency of Particular Region}

Power system is in balanced condition at nominal frequency of the system, but frequency of the power sector deviates from the nominal value due to imbalance between demand and supply of system. If at any stage, electrical power available is more than 
required power, then frequency of the system becomes more than the nominal frequency. On the other hand, if the power available is less than the required power, then frequency of the system becomes less than the nominal frequency. $D_{f}$ is demand of the some particular area at current frequency $f$, whereas $D_{\text {nom }}$ is the demand or load of the system at nominal frequency and $\mathrm{f}_{\text {nom }}$ is nominal frequency of the system.

\subsection{Determination of INADVERTENT INTERCHANGE Price}

In day a head market, hourly bids are taken from suppliers and load serving entities to discover an hourly locational marginal price (LMP). Based on settlement in day-ahead market an hourly schedule for next day is prepared. This schedule represents a perfect balance of supply and demand resulting in nominal frequency. Any deviations from schedule will result in deviation from nominal frequency. Locational Marginal Price is the price of power at nominal frequency.

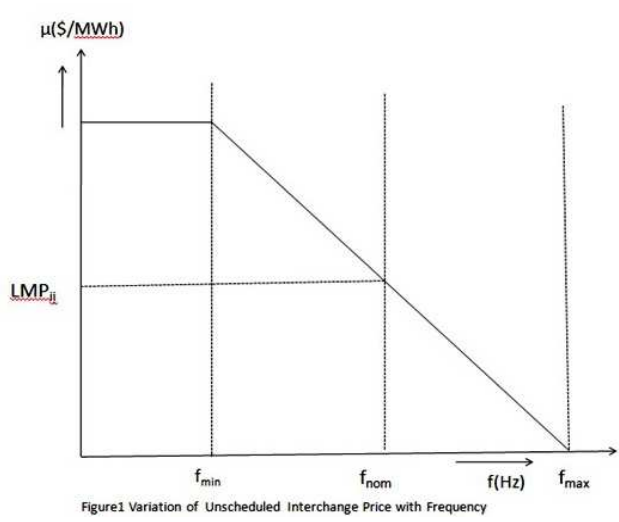

Figure1 depicts the variation of frequency based inadvertent interchange price with frequency. Taking LMP as a reference point we can construct a curve similar to INADVERTENT INTERCHANGE curve to price deviations in schedule for the proposed real-time market, Frequency dependent Inadvertent Interchange Price curve. This curve joins two fixed points on price vs. frequency chart. Let $\left\{\mathrm{f}_{\min }, \mathrm{f}_{\max }\right\}$ be the range of frequency over which real-time price will vary. The real-time price called as Frequency dependent Inadvertent Interchange Price is higher for frequencies below nominal value (i.e. when demand is greater than supply) and lower for frequencies above nominal value (i.e. when supply is greater than demand). Let $f_{\text {nom }}$ be the nominal frequency, $f$ be the current frequency and fmax be the maximum frequency, where LMPij is the locational marginal price in ith trading interval at $j^{\text {th }}$ bus.

Frequency based Inadvertent Interchange price $\mu(\$ / M W h)$ at any frequency $f$ can be determined by the expression

$$
\begin{aligned}
& \mu=\operatorname{LMP}_{\mathrm{ij}} \times \frac{\mathrm{f}_{\max }-\mathrm{f}}{\mathrm{f}_{\max }-\mathrm{f}_{\text {nom }}}=\mathrm{LMP}_{\mathrm{ij}} \\
& \times \text { Frequency Deviation Ratio }
\end{aligned}
$$

\subsection{Determination of Profit/ Loss at any Bus}

Frequency of the grid is a function of supply-demand imbalance and not in control of one particular market participant. The profit (loss) to any electricity market participants is the difference of total revenue received and the cost of power purchase or generation cost in real time market. Therefore Profit/Loss in Inadvertent Interchange mechanism at any load or generator bus can be defined as a function of deviation of power. $\Delta P=\left(P_{a c t}-P_{s c h}\right)$ where $\Delta P$ is the deviation of power from the schedule in MW and is calculated by subtracting declared schedule from the actual drawal for each 15 minutes time block. Loss or Profit $(\$ / \mathrm{h})$ in $i_{\text {th }}$ trading interval at particular $j_{t h}$ bus due to inadvertent interchange of power in the real time market.

$$
\alpha_{i j}(\Delta P)=\Delta P \times\left(\text { UIprice }_{i j}-L M P_{i j}\right)
$$

where UIprice $e_{i j}$ is inadvertent interchange price of $j_{\text {th }}$ bus in $i_{\text {th }}$ trading interval in the real time market. $L M P_{i j}$ is locational marginal price of $j_{t h}$ bus in $i_{t h}$ trading interval in the real time market. Net Profit or loss of the system in first trading interval is given by

$$
\begin{aligned}
& \sum_{j, i=1} \alpha_{i j} \\
& =\quad \text { Net Profit or Loss of the system }
\end{aligned}
$$

\section{STEP BY STEP PROCEDURE}

The main steps of the proposed algorithm can be described as follows:-

Step1: Read the system data of deregulated double auction modified IEEE 30- bus system.

Step2: Run the optimal power flow program in matpower for optimal values of generation and demand

at generator and load buses and evaluate locational marginal price at various buses of the system. Under this balance condition, system frequency will be nominal thereby Inadvertent Interchange Price be equal to locational marginal price.

Step3: Note the uncommitted amount of power at various load buses in the pool, bilateral and multilateral transactions in the subject cited system.

Step4: Assume the prevailing frequencies in each of these three areas of the deregulated system

Step5: Calculate the Inadvertent interchange price at various buses of the system by equation (1).

Step6: Run again the optimal power flow for optimization of new generation at various generations

buses corresponding to new load at load buses due to inadvertent power exchange. 
Step7: Determine the inadvertent amount $(\$ / \mathrm{h})$ received from each defaulter load of the pool, bilateral and multilateral at each bus for creating the disturbance in the system by equation (2).

Step 8: Determine the inadvertent amount $(\$ / \mathrm{h})$ paid to generator buses of the pool, bilateral and multilateral for balancing the system by equation (2).

Step9: Determine the net profit/ loss in the pool and transactions by taking the difference between the payment received from the load buses and amount paid to generator buses. The flow chart of the proposed approach is represented in Figure 2

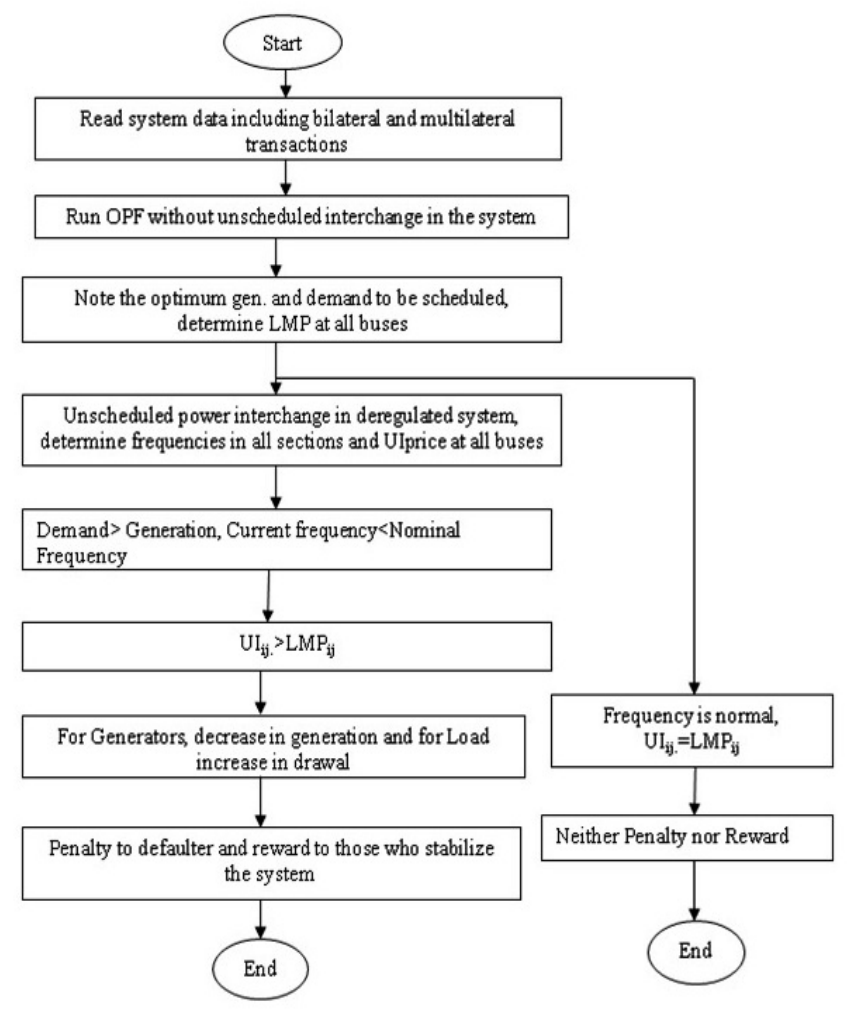

\section{METHODOLOGY OF WORK}

The proposed frequency based technique has been tested and analyzed on modified IEEE-30 bus test system shown in figure 3 . It consists of 30 buses, 41 branches and six generating units. The whole deregulated power system has been divided into three sub sections; the prevailing frequencies in these areas can be assumed by trend of the inadvertent interchange of power in these areas with the help of equation. Then corresponding inadvertent interchange (UI) prices are calculated at each bus with the help of equation (1). First of all, run optimal power flow in matpower software for scheduled power flow in the system for optimal generation and demand at generator and load buses and Locational Marginal Price (LMP) at each bus of the system, then calculate UI price at each bus of competitive electricity market. Now due to Inadvertent Interchange of power at various buses of the system, there will be corresponding increase in generation at various buses of the system; these optimal values of generations can be found out by running the optimal power flow again. Inadvertent Interchange payment paid by load bus and received at every generator is calculated on the basis of prevailing frequency in that section of the power sector by equation (3). Net Profit or loss in the system comprising of pool, bilateral and multilateral transactions can be calculated by equation (4). Difference between payment received from load buses and payment paid to generator bus may be called as part of Social Benefit (SB) of the system.

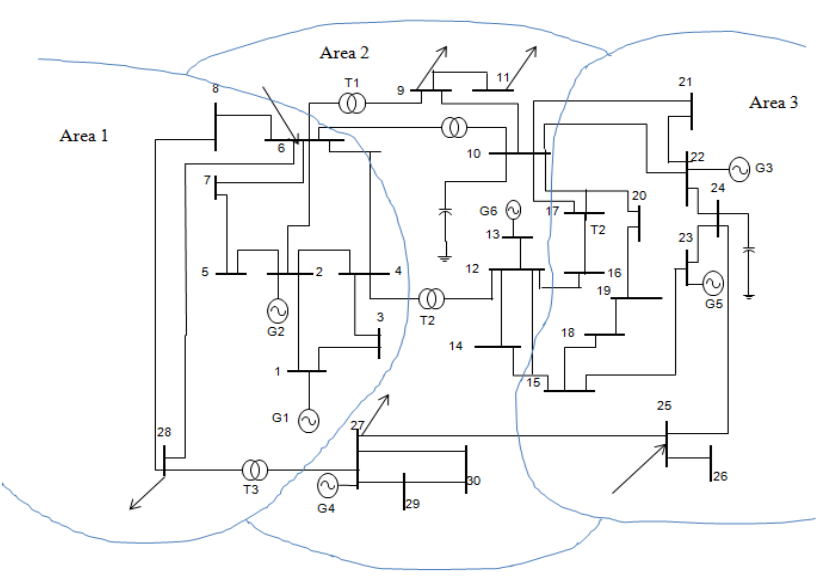

Fig 3 Single Line Diagram of Modified IEEE-30 Bus System with Bilateral and Multilateral Transactions

A single-line diagram of modified IEEE 30 bus system with bilateral and multilateral transactions is shown in Fig. 3. The proposed approach dependent on frequency based tariff has been tested and analysed on this system. Double auction deregulated system has been taken for this purpose. All the six generators connected at buses 1, 2, 22, 27, 23 and 13 are assumed to offer the cost characteristics however, there are bidding from some demand sided buses. Bilateral transactions are additional to the pool transaction, these transaction occurs in deregulated system due to the bilateral exchange of power between one buying and one selling company. Multilateral transactions are an extension of bilateral transactions. These are also charged on the basis of LMP and UI price, because these entities are also not bidding. In this study, two transactions, one bilateral transaction of amount $2 \mathrm{MW}$ and one multilateral transaction of $10 \mathrm{MW}$ are considered for the simulation. Generator and load of bilateral transaction are connected at bus number 6 and 22 whereas those of multilateral transaction is connected at bus number 25 whereas loads are connected at and $9,27,28$ respectively. 
Frequency of the area 1, 2 and 3 has been assumed 49.86, 49.81 and $49.85 \mathrm{~Hz}$ respectively as actual demand is more than the scheduled demand.

Inadvertent Interchange price in area 12,3 are $\mathrm{UI}_{\text {price }}=\mathrm{LMP}^{*}$ Frequency Deviation Ratio by equation (1) Frequency Deviation Ratio of an area is dependent on current, maximum and nominal frequencies of that particular area. Frequency ratio of area 1, 2 and 3 are calculated as 1.68, 1.95 and 1.75 respectively.
Table 1 show Inadvertent Interchange Revenue received from load buses of the pool as well as transaction for inadvertent power interchange by them. The inadvertent interchange payment paid by each demand bus is calculated by multiplying the difference between UI Price and LMP price with inadvertent power of at that particular demand bus. The overall inadvertent interchange payment paid by all such participants are calculated by taking summation of payment paid by each individual demand bus. Fixed power demands are also penalized on the same basis, because these entities are not bidding.

Table 1 Inadvertent Interchange Revenue received from load buses of the pool as well as transaction

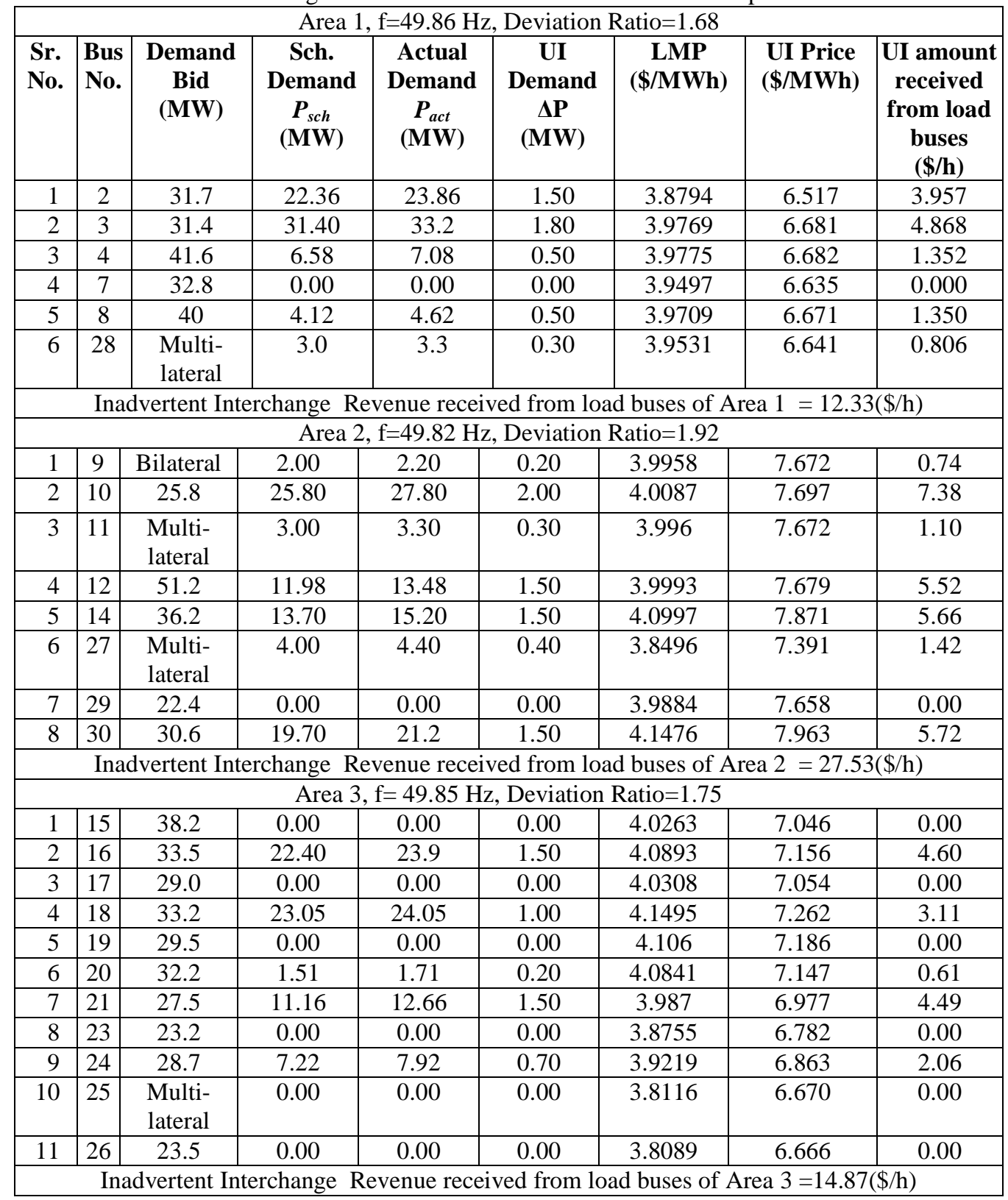


Net Inadvertent Interchange received from all defaulters load buses of area 1 , area 2 and area 3 of the pool $=54.73(\$ / \mathrm{h})$

Table 2 shows Inadvertent Interchange Revenue paid to generator buses of the pool as well as transaction for balancing the system. The inadvertent interchange payment received by each generator bus is calculated by multiplying the difference between Inadvertent Interchange Price and LMP price with inadvertent power at that particular generator bus. The overall inadvertent interchange payment paid to all generators is calculated by taking the summation of payment received by each individual generator.

Table 2 Inadvertent Interchange Revenue paid to generator buses of the pool as well as transaction

\begin{tabular}{|c|c|c|c|c|c|c|c|c|}
\hline \multicolumn{9}{|c|}{ Gen. Buses of All areas of pool and transaction } \\
\hline $\begin{array}{l}\text { Sr. } \\
\text { No. }\end{array}$ & Bus No. & $\begin{array}{c}\text { Sch. Gen. } \\
P_{\text {sch }} \\
(\mathrm{MW})\end{array}$ & $\begin{array}{l}\text { Actual } \\
\text { Gen. } P_{a c t} \\
(\mathrm{MW})\end{array}$ & $\begin{array}{c}\text { UI Gen. } \\
\Delta \mathrm{P} \\
(\mathrm{MW})\end{array}$ & $\begin{array}{c}\text { Frequency } \\
\text { Deviation } \\
\text { Ratio }\end{array}$ & $\begin{array}{c}\text { LMP } \\
\text { (\$/MWh) }\end{array}$ & $\begin{array}{c}\text { UI } \\
\text { Rate } \\
(\$ / \mathrm{MWh})\end{array}$ & $\begin{array}{l}\text { UI amount } \\
\text { paid to } \\
\text { gen.buses } \\
(\$ / \mathrm{h})\end{array}$ \\
\hline 1 & $1(\mathrm{~A} 1)$ & 46.45 & 50.33 & 3.89 & 1.68 & 3.8579 & 6.481 & 10.20 \\
\hline 2 & 2(A1) & 60.84 & 65.40 & 4.56 & 1.68 & 3.8794 & 6.517 & 12.03 \\
\hline 3 & $13(\mathrm{~A} 2)$ & 19.99 & 22.64 & 2.66 & 1.92 & 3.9993 & 7.679 & 9.79 \\
\hline 4 & $22(\mathrm{~A} 3)$ & 23.77 & 25.55 & 1.77 & 1.75 & 3.9713 & 6.950 & 5.27 \\
\hline 5 & $23(\mathrm{~A} 3)$ & 17.51 & 16.43 & -1.08 & 1.75 & 3.8755 & 6.782 & -3.14 \\
\hline 6 & $27(\mathrm{~A} 2)$ & 35.95 & 40.42 & 4.47 & 1.92 & 3.8496 & 7.391 & 15.83 \\
\hline 7 & 6(A1) & 2.0 & 2.2 & 0.2 & 1.68 & 3.9712 & 6.672 & 0.54 \\
\hline 8 & $25(\mathrm{~A} 3)$ & 10 & 11 & 1.0 & 1.75 & 3.8116 & 6.670 & 2.86 \\
\hline
\end{tabular}

Net Inadvertent Interchange Amount paid to all generator buses of area 1 , area 2 and area 3 of the Pool and transaction $=$ $53.38(\$ / \mathrm{h})$. Net Profit to ISO due to implementation of Inadvertent Interchange in deregulated system $=1.35(\$ / \mathrm{h})$.

\section{OBSERVATIONS}

The following observations have been made by the simulation with the proposed technique. In the deregulated model of the deregulated power system consisting of pool bilateral transactions, prevailing frequencies of area 1, 2 and 3 become $49.86 \mathrm{~Hz}, 49.82 \mathrm{~Hz}$ and of $49.85 \mathrm{~Hz}$ respectively due to overdrawal of power by defaulters loads. These loads have been heavily penalized as per inadvertent interchange price determined by equation (2) dependent on the current frequency of the region. Generator who are providing extra power into the system for the compensation of the inadvertent load, have received extra huge amount of money as profit dependent on frequency, as the frequency of the system becomes less than the nominal frequency. Finally evaluate the profit/loss to ISO in the pool, bilateral and multilateral transaction due to implementation of inadvertent interchange pricing is $1.35 \$ / \mathrm{h}$.

\section{CONCLUSION}

This paper presents an approach for determination of inadvertent interchange revenue at various generator and load buses in the competitive electricity market model consisting of pool, bilateral and multilateral transactions. In this paper a double auction competitive electricity market model has been analyzed with modified IEEE-30 bus test system. Frequency has been assumed in each region by trend of the inadvertent interchange of power in pool, bilateral and multilateral transactions. Frequency linked tariff has been applied for inadvertent variation of power in pool, bilateral and multilateral transactions. Impact of inadvertent interchange of power based upon the frequency variation has been analyzed on this bus system. In this method, those defaulters load market participants have paid huge amount who are diverting from their schedule entitlement in the market and creating the disturbance in the system by varying the frequency of the system as well as those generator participants are rewarded who maintains the frequency of the system in the nominal range by providing extra power in the competitive market other than their committed entitlements.

\section{REFERENCES}

[1] Sood Y.R., Padhy N.P. and Gupta H.O., “Advancement in Power System Engineering Education and Research 
with Power Industry Moving Towards Deregulation", IEEE Power Engineering Society General Meeting2004., Vol.1, June 2004, pp. $71-76$.

[2] Bhushan B., "ABC of ABT: A Primer on AvailabilityTariff”,[Online].Available: http://www.nrldc.in.

[3] http://www.kalkitech.com/downindex/ Introduction to ABT.pdf.

[4] http://www.cercind.gov.in/2012/sharing_regulation/UI_ Amendments_2011_dated_15.2.2012.pdf

[5] http://www.iexindia.com.

[6] http://powermin.nic.in/transmission/pdf/Indian_Electrici ty_Grid_Code.pdf.

[7] Bhushan B., Roy and A. Pentayya, P., "The Indian Medicine", IEEE Power Engineering Society General Meeting, 2004, Vol. 2, June 2004, pp. 2336 - 2339.

[8] Bhushan B., "Overcoming Power Shortage through U.I.", www.srldc.org/Downloads/ Opstui.doc

[9] Chanana S. and Kumar A., "Proposal for a Real time Market based on the Indian Experience of Frequency Linked Prices", IEEE Energy 2030, Nov. 2008, pp. 1-5.

[10] Zhong J. and Bhattacharya K., "Frequency linked pricing as an instrument for frequency regulation in deregulated electricity markets", IEEE PES General Meeting, Toronto, Canada, July 2003, pp.566-571.

[11] Sood Y.R., Padhy N.P. and Gupta H.O., "Deregulated model and locational marginal pricing",Electric Power Systems esearch, Volume 77, Issues 5-6, April 2007, pp. 574-582

[12] Deshmukh, S.R., Doke, D.J. and Nerkar, Y.P., “Optimal Generation Scheduling under ABT using Forecasted Load and Frequency", $\quad$ Power System Technology and IEEE Power India Conference 2008, pp. 1 - 6.

[13] Suryanarayanan S., Farmer R. G. , Heydt G. T., and S. Chakka, "Estimation of Unscheduled Flow and Contribution Factors based on Lp Norms", IEEE Transactions on Power Systems, Vol. 19, No. 2, May 2004, pp.1245-1246.

[14] http://www.pserc.cornell.edu/matpower.

[15] Lively M. B., "Creating an automatic market for unscheduled electricity flows", The National Regulatory Research Institute [Online] Dec. 2005, pp. 1-8. Available:http://www.livelyutility.com/ library.php.

[16] Soonee S.K., Narasimhan S.R. and Pandey V., Significance of unscheduled interchange mechanism in the Indian electricity supply industry," Dept. of Electrical Engineering, ITBHU, ICPSODR- 2006, [Online] Available: http://www.nrldc.org/docs/documents/Papers/Significan ce_of_UI.pdf

[17] Lively M. B., "Pricing intermittency, loop flow, and other forms of unscheduled flows of electricity," presented at $A$ Web Based Seminar by Leonardo ENERGY, 2007. [Online]. Available: http://orig.leonardo-energy.org/drupal/node/1517.
[18] Lively M. B., "Profit-enhancing seam management: a white paper on pricing the unscheduled flows of electricity across the seams between utilities using a geographically differentiated auction of inadvertent interchange. Gaithersburg, MD, 2001. [Online]. Available: http://www.naesb.org/pdf/weq_iiptf080603w3.pdf.

[19] Suryanarayanan S., Heydt G. T., Farmer R. G., and Chakka S., "An estimation technique to assign contribution factors for loop flows in an interconnected power system," Electric Power Components and Systems, vol. 32, no. 8, 2004, pp. 813-826.

[20] Suryanarayanan S., Heydt G. T., "Modification to contribution factor formula for unscheduled flows," IEEE Transactions on Power Systems, vol. 23, no. 2, May 2008, pp. 809-810.

[21] Suryanarayanan S., Montgomery D., and Heydt G. T., "Considerations for implementing tag schedules in transmission circuits," IEEE Transactions on Power Systems, vol. 20, no. 1, 2005, pp. 523-524. 